\title{
Can developing countries leapfrog the centralized electrification paradigm?
}

Todd Levin $^{{ }^{*}}$, Valerie M. Thomas ${ }^{2,3}$

\author{
Affiliations: \\ ${ }^{1}$ Energy Systems Division, Argonne National Laboratory \\ ${ }^{2}$ School of Industrial and Systems Engineering, Georgia Institute of Technology \\ ${ }^{3}$ School of Public Policy, Georgia Institute of Technology \\ *Correspondence to: 9700 S. Cass Ave, Bldg. 202. Lemont, IL 60439. tlevin@anl.gov.
}

Keywords: Solar home system; grid extension; global energy access; decentralized electrification; international energy development

Abstract: Due to the rapidly decreasing costs of small renewable electricity generation systems, centralized power systems are no longer a necessary condition of universal access to modern energy services. Developing countries, where centralized electricity infrastructures are less developed, may be able to adopt these new technologies more quickly. We first review the costs of grid extension and distributed solar home systems (SHSs) as reported by a number of different studies. We then present a general analytic framework for analyzing the choice between extending the grid and implementing distributed solar home systems. Drawing upon reported grid expansion cost data for three specific regions, we demonstrate this framework by determining the electricity consumption levels at which the costs of provision through centralized and decentralized approaches are equivalent in these regions. We then calculate SHS capital costs that are necessary for these technologies provide each of five tiers of energy access, as defined by the United Nations Sustainable Energy for All initiative. Our results suggest that solar home systems can play an important role in achieving universal access to basic energy services. The extent of this role depends on three primary factors: SHS costs, grid expansion costs, and centralized generation costs. Given current technology costs, centralized systems will still be required to enable higher levels of consumption; however, cost reduction trends have the potential to disrupt this paradigm. By looking ahead rather than replicating older infrastructure styles, developing countries can leapfrog to a more distributed electricity service model.

\section{Introduction}

Direct electricity access eludes almost $20 \%$ of the world's population, the large majority of whom live in rural regions of developing countries and providing universal electricity access has become a fundamental humanitarian goal of our generation (IEA 2014b). This imperative has been formalized through the Sustainable Energy for All (SE4AII) initiative that was launched by the United Nations in 2012 with the objective of achieving universal access to modern energy services by 2030. In 2013 an initial Global Tracking Framework was published, which formalized this goal and provided a consensus methodology for measuring and tracking progress towards its achievement. ${ }^{1}$ It was estimated at the time that investments of $\$ 60$ to $\$ 160$ billion dollars per year above current levels may be required in order to meet these goals (Angelou et al. 2013), and it is vital that any such investments are channeled to support technological and institutional solutions that are as forward-looking and cost-effective as possible. A second edition of the Global Tracking Framework was published in 2015 and provides an update on progress

\footnotetext{
${ }^{1}$ The Global Tracking Framework also established two goals in addition to achieving universal access to modern energy services. These are doubling the global rate of improvement in energy efficiency and doubling the share of renewable energy in the global energy mix. While all three are worthy pursuits, the first is of primary relevance to this work.
} 
towards meeting the objectives that were established in the first edition (IEA and World Bank 2015). The findings of this report unfortunately indicate that the rate of progress over the two a year tracking between 2010 and 2012 falls "substantially short" of what would be required to obtain the SE4All objectives by 2030. It is therefore more important than ever that cost-effective pathways for increasing global energy access in a sustainable manner are identified and pursued.

Traditionally, nations seeking improved electricity access pursue centralized electrification. This strategy requires large upfront infrastructure investments in order to take advantage of economies of scale at large coal, natural gas, nuclear or hydroelectric generation facilities and has seen tremendous success over the past century throughout the developed and developing world. However, due to cost reductions of new distributed technologies such as rooftop solar panels, small wind turbines, and energy storage, the economics that motivated a centralized approach are changing. This is particularly the case in regions where electricity consumption is low and the costs of grid expansion are high (Levin and Thomas 2012). In the developed world, the rapid introduction of utility-scale renewable generation is driving down wholesale electricity prices and reducing revenues for large nuclear, coal and natural gas generators, while at the same time increasing the cost of ensuring system reliability (Ela et al. 2014). Consumers are also increasingly adopting decentralized generation technologies and reducing their reliance on the traditional centralized grid model. This combination of factors may force a fundamental shift in way the utilities and governments approach the long-term planning and development of power systems infrastructure.

In the developing world, centralized power systems have still yet to reach a significant portion of the population. Furthermore, even those who do have access to electricity receive no tangible benefit if such access is not affordable, reliable, or functioning (Mainali et al. 2014). Throughout the developing world many poor families reside in "electrified" regions, but still lack electricity for economic reasons. Electric grids are also often extremely unreliable in the developing world due to generation capacity shortages, poor transmission and distribution infrastructure, and a host of other operational issues. In many developing countries outages can be an almost daily occurrence and many homes and businesses maintain backup diesel generators even when they have grid access (The World Bank 2012). While many of these problems could be addressed through additional generation and infrastructure investments, such investments have not materialized for a variety of reasons. Therefore, many consumers continue to be reliant on costly personal generators to guarantee reliable access to electricity. Because of these complexities, the concept of "energy access" does not have a universally agreed upon definition and the binary metrics that are commonly used to evaluate energy access programs can often be misleading (Angelou et al. 2013). For example, one metric used in India considers an entire village to be electrified if only $10 \%$ of the homes have access to electricity, but does not consider isolated homes powered by individual solar home systems (SHS) to be electrified (Palit and Chaurey 2011). Similarly, many people who do not have direct access to electricity electricity in the home - still have reasonable access to cell phones, battery powered lights and other electronic devices that may be charged at distributed charging stations. Many of these challenges are exacerbated by the fact that data on energy access and usage are scarce in many developing countries. This makes it harder to for policy makers to identify high priority areas for public intervention and also to evaluate the effectiveness of programs that are designed to increase energy access. With this understanding in mind, the SE4All initiative has also proposed a multi-dimensional methodology to measure energy access across five consumption tiers and eight energy attributes (Angelou et al. 2013; Angelou and Bhatia 2014). This methodology extends well beyond the traditional metrics annual energy consumption and a binary energy access indicator, incorporating a range of other factors into a multi-tier classification of energy access. The considered attributes initially included peak availability, duration of availability, evening supply, affordability, legality, and quality of access. These have been further expanded in the second edition of the Global Tracking Framework to also include reliability and health and safety (IEA and World Bank 2015). 
Moving beyond the traditional definition of energy access towards one that accounts for reliability and affordability, it becomes clear that centralized and distributed electrification strategies are not always perfect substitutes for one another (Murphy et al. 2014). As a result, distributed approaches may be preferred in some regions even when centralized strategies appear to be the lowest cost option (Levin and Thomas 2014a). Centralized approaches may still dominate in some regions, however at a national scale it will likely be the case that a socially and economically optimal power system will contain both centralized and distributed components. Therefore, developing countries have a unique opportunity to leapfrog the traditional centralized model and transition directly to a more distributed approach to electrification, particularly in regions that are not currently electrified. A comparison can be drawn to the rapid adoption of cellular telephone technologies throughout much of the developing world over the past decade, which bypassed the traditional landline model.

Policy makers are increasingly becoming aware of the potential for distributed electrification strategies to provide services in regions that have traditionally been too costly to serve with grid expansion (Narula et al. 2012). However, distributed rural electrification programs are generally poorly integrated with their grid-based counterparts (Urpelainen 2014), and often are not afforded the same level of large-scale institutional support. In South Asia for example, it has been observed that most distributed rural electrification programs are grant and donor driven, but the few that have received significant institutional support at the state or national level tend to be the most successful (Palit and Chaurey 2011). Grid-based electrification programs that are developed through the centralized utility model are also easier to subsidize than the more disaggregated, community-scale approaches that are often pursued by distributed programs. This effect has been quantified in Laos where subsidies for grid-based electrification usually exceed $70 \%$ of total costs, while those for distributed electrification average only $26 \%$ of total costs (Martin and Susanto 2014). In rural regions of Thailand, homes receive $50 \mathrm{kWh}$ of free electricity from the grid each month at a cost to the government of over US\$30 million; this level of government sponsored financial support is simply not available for distributed electrification programs (Martin and Susanto 2014). In Ghana a similar "lifeline" tariff is offered, which charges all customers who consume less than 50 $\mathrm{kWh}$ in a month a flat fee of approximately $\$ 1.25$ (World Bank 2010), well below cost recovery in rural regions.

Over the last decade Brazil has embarked upon an aggressive and fairly successful universal electrification campaign. However, the current focus on grid-expansion has reached its economic limits due to the extremely high costs of grid-expansion in the rural Amazon region. Off-grid approaches are likely necessary to reach many of the 500,000 households that still lack electricity access. Electrified homes in these regions are currently supplied by isolated diesel generators and mini-grids that exist outside of the institutional electrification framework in Brazil (van Els et al. 2012). As a result, it has been difficult for the Brazilian government to provide direct, or indirect, subsidies for these distributed approaches to rural electrification. In an effort to address these issues and achieve truly universal electrification, the government has recently expanded their program to provide support for smaller third-party organizations that are able to serve these rural populations with distributed technologies (Gómez and Silveira 2015). Such an institutionally centralized approach to implementing distributed electrification technologies may enable the Brazilian or other governments to more effectively cross-subsidize energy access in regions that are costly to serve through grid expansion. For additional discussion on the Brazilian electrification program see (Zerriffi 2008; Gomez and Silveira 2010) and for the cases of several national rural electrification programs, including Brazil, see (Zerriffi 2011). 
By offering or mandating low tariffs for grid electricity in rural regions, governments are either explicitly or implicitly providing subsidies for centralized, grid-based approaches to electrification. In situations where electricity consumption levels are low or grid connection costs are high, the grid subsidy may exceed the entire cost of electricity provision through a distributed technology such as a solar home system (Levin and Thomas 2014b). We therefore present an analysis of the unsubsidized costs of electricity provision through both a centralized grid and through distributed SHS technologies. We first review SHS costs that have been reported in a number of different countries in recent years as well as the costs associated with grid expansion, showing that both of these costs can vary significantly in different geographical regions. We then develop a general analytic framework for analyzing the choice between grid expansion and implementing distributed electrification technologies.

A number of studies have examined the choice between grid expansion and distributed electrification technologies by conducting detailed analyses of specific regions and also more generally (Parshall et al. 2009; Deichmann et al. 2011; Szabó et al. 2011; Levin and Thomas 2012, 2013; Sanoh et al. 2012; Kemausuor et al. 2014). Rather than performing a detailed original case study analysis of electric infrastructure development in a particular location, we instead develop a broader analytic framework that can be used to identify potential economic tipping points between these two centralized and decentralized electrification paradigms. We then draw upon grid expansion costs that have been previously calculated for three specific regions to demonstrate this framework. For simplicity and to demonstrate proof of concept, we consider just one distributed electrification technology, a SHS. However, this framework could easily also be applied to analyze other distributed technologies or a hybrid approach utilizing village-scale solar arrays, wind turbines, or small hydroelectric generators with power distribution through localized micro-grids.

\section{Materials and methods}

All cost data reported in this paper have been converted into 2015 U.S. dollars based on the United States Consumer Price Index (CPI). Cost data that were originally reported in a local currency were converted to U.S. dollars based on the conversion rate at the time those costs were reported ${ }^{2}$. These were then adjusted into cost year 2015 dollars based on the CPI. As many currencies fluctuate significantly versus the U.S. dollar, in some cases this can lead to different values than would be obtained by converting directly from the local currency at present conversion rates.

\subsection{Solar Cost Review}

Solar power generation has seen rapid growth throughout the world over the past decade, as the cost of manufacturing continues to fall as institutional support grows. In the industrialized world, Germany provides the earliest example of this growth and solar photovoltaic (PV) technologies provided $6.9 \%$ of Germany's net electricity consumption in 2014 (Wirth 2015). The United States still lags behind Germany in terms of solar generation - solar technologies provided less than 1\% of U.S. generation in 2014 - but has seen significant growth in recent years (EIA 2015a). Approximately $18,000 \mathrm{MW}$ of new grid-connected solar capacity was added in the United States between 2008 and 2014 (MITEI 2015), and total installed capacity is projected to double from 20,000 to 40,000 MW over the next two years (SEIA 2014). Bangladesh has led the charge towards solar development in the developing world, thanks in large part to Grameen Shakti and its efforts to reduce institutional barriers by providing microfinancing for individual SHSs. Through continued support from the Rural Electrification and Renewable Energy Development

\footnotetext{
${ }^{2}$ http://www.xe.com/currencytables/
} 
Project, it is expected that 2.5 million people in rural Bangladesh will be reached by a SHS by 2018 (World Bank 2014). Similar growth is now being witnessed in India and interest has also been growing throughout Africa and the rest of the world.

\subsubsection{Module and BOS}

The installed cost of distributed solar generation systems can be broken into two primary components, the cost of the PV module itself, and the so-called balance-of-system (BOS) costs, which include the system inverter, controller, other hardware, installation, permitting, regulatory compliance and a range of potential other soft costs. In the developed world, distributed solar PV systems are typically installed in buildings that already have a connection to the grid, and the additional cost of integrating the solar generation is included in the BOS costs. In this arrangement, the energy generated by the PV system is used to offset consumption from the grid, usually during peak hours when the sun is shining, and the grid connection is available to provide power during periods when solar power is not available. This is often not the case in the developing world, where solar PV systems are increasingly being considered as a standalone alternative to grid expansion in regions that do not currently have access to the grid. Therefore, a complementary storage system is also required to ensure that power is available throughout the day and night.

Due to technological advancements, increased demand, and growing economies of scale, the cost of solar modules has decreased dramatically in recent years. In the United States the cost of a solar module was approximately $\$ 4.00$ per peak watt (Wp) in 2008 and by 2014 that cost had decreased by almost $85 \%$ to $\$ 0.65$ per Wp (MITEI 2015). As solar PV modules have increasingly become global commodities, similar cost reductions have been experienced around the world.

BOS costs vary much more significantly from region to region, and are also dependent on the size of the installation. In the United States these costs have been estimated to be roughly $\$ 1.15$ per Wp for utility-scale applications and $\$ 2.60$ per Wp for residential applications, although actual costs may be higher or lower in areas that are more or less supportive of solar development. All told, cost estimates for typical installed systems in the United States are therefore roughly $\$ 1.80$ per Wp for utility-scale applications and $\$ 3.25$ per Wp for residential applications. Actual reported prices for installed systems are somewhat higher for residential systems, exceeding $\$ 4.00$ per $\mathrm{Wp}$, a difference that can be largely attributed to imperfect competition in the solar installation market. In Germany, where solar markets are more advanced, BOS costs are generally lower than in the United States, as low as $\$ 1.40$ per Wp for residential applications, for an average reported installed cost of roughly $\$ 2.05$ per Wp in 2013 (MITEI 2015). Consumer prices may be further reduced by subsidies that are available for solar technologies in the United States and Germany; however our analysis focuses on unsubsidized costs.

In the developing world, residential and small commercial consumers more frequently purchase a bundled SHS which typically include all necessary components, installation, appropriate battery storage, and in some cases energy efficient appliances such as LED lighting, fans, radios or televisions. These systems are growing in popularity around the world, but costs can vary wildly. It is also difficult to draw direct cost comparisons between SHS costs in different areas as they are commonly delivered through rental agreements or various financing mechanisms, and total system costs may depend on the details of these arrangements.

The organization that has been at the forefront of the rapid SHS penetration in Bangladesh, Grameen Shakti, offers systems that vary in capacity from $10 \mathrm{Wp}$ to $135 \mathrm{Wp}$ and in cost from $\$ 7.70$ per Wp to \$3.71 per Wp (Grameen Shakti 2015). These systems all include inverters and controllers, appropriately sized battery storage, a number of appliances, a 20 year warranty on the solar panel, and a five year warranty on the battery. In India where SHS 
markets are also becoming mature, similar SHSs are being delivered through financing schemes coordinated by the Ministry of New and Renewable Energy (MNRE) and the National Bank for Agriculture and Rural Development (NABARD). In 2011 the indicative costs for these systems were roughly $\$ 7.13$ to $\$ 6.96$ per Wp for systems ranging in capacity from $10 \mathrm{Wp}$ to $200 \mathrm{Wp}$ (NABARD 2011). SHS costs are generally somewhat higher in other regions of the world with less mature markets. Smaller systems are typically more expensive on a per unit basis. A review of "pico PV systems" - those with $10 \mathrm{Wp}$ capacity or less - in various locations throughout the world found costs to be roughly \$21.20 per Wp in 2015 dollars (Lysen 2013).

Reported SHS unit costs in a range of other locations in the developing world are detailed in Table 1 and Figure 1. These reflect actual reported costs from different real-world programs and price lists, as opposed to generic modeling assumptions that have been made for various studies and analyses. When possible, the listed year represents the year in which the specific project was installed or the listed price was offered. However, some data sources do not explicitly provide this information, in which case we default to the publication year of the reference. Additional care should be exercised in comparing these costs, as systems may include different storage capacity or appliances. In some cases administrative costs may be incorporated into the listed system cost, while in other cases these may be incorporated into financing costs that are considered separately. Some prices may also reflect a certain degree of subsidization, but unfortunately most of the sources used to compile these cost data do not specifically discuss potential subsidies or other programmatic support. A regulatory environment that is supportive of distributed solar can also reduce BOS costs, and therefore the total cost of a project, as is evident from the difference in installed costs for solar in the U.S. and Germany. Such indirect cost reduction factors are also not explicitly discussed in most of these data sources.

\subsubsection{Storage}

It is more difficult to estimate the cost contribution from the storage component of a SHS as costs are often reported only for the system as a whole. The relative cost of storage also depends upon several factors, namely the technology that is used (i.e. lead-acid or lithium-ion) and the storage capacity of the battery. Broadly speaking, a SHS for residential or small commercial applications in the developing world will typically include a 12 volt leadacid battery with approximately $12 \mathrm{Wh}$ (1 Ah) of storage for each Wp of solar panel generation capacity. Table 1 also shows the component of total SHS cost that is attributable to the battery for several systems where such a cost breakdown was reported. The storage to generation ratio provides a measure of the relative size of the storage component of each system. It would likely be expected that batteries in systems with high storage to generation ratios would account for a relatively larger portion of the total system cost. The storage capacities of systems without this cost breakdown are also included to provide examples of typical battery sizing for a SHS in different regions. These data indicate that storage costs can be highly variable. For example the storage component of the $80 \mathrm{Wp}$ system analyzed in Morocco accounted for a much higher share of total costs than the storage component of the $75 \mathrm{Wp}$ system analyzed in Uganda, despite both systems having the same storage capacity. The primary causes of such discrepancies are not immediately clear from the information that has been made available. We assume for our analysis that the storage component accounts for $20 \%$ of the total SHS cost and must be replaced every five years. Therefore Table 1 should be considered to provide a broad comparative overview of reported SHS prices in various parts of the world. If precise cost information is desired for a specific location it would be prudent to conduct a more detailed review and develop an understanding of the subsidies and other forms of support that may be involved. 


\begin{tabular}{|c|c|c|c|c|c|c|c|c|c|c|}
\hline Year & Country & $\begin{array}{c}\text { PV } \\
\text { Capacity } \\
\text { (Wp) }\end{array}$ & $\begin{array}{l}\text { System } \\
\text { Cost (\$) }\end{array}$ & $\begin{array}{l}\text { Unit } \\
\text { Cost } \\
\text { (\$/Wp) }\end{array}$ & $\begin{array}{c}\text { Battery } \\
\text { Capacity } \\
\text { (Ah) }\end{array}$ & $\begin{array}{l}\text { Battery } \\
\text { Cost (\$) }\end{array}$ & $\begin{array}{l}\text { Battery } \\
\text { Unit } \\
\text { Cost } \\
\text { (\$/Ah) }\end{array}$ & $\begin{array}{l}\text { Battery } \\
\text { Cost (\% } \\
\text { of total) }\end{array}$ & $\begin{array}{c}\text { Storage to } \\
\text { Generation } \\
\text { Ratio } \\
(\mathrm{Wh} / \mathrm{Wp})\end{array}$ & Source \\
\hline 2015 & Bangladesh & 10 & $\$ 77.02$ & $\$ 7.70$ & 15 & - & - & - & 1.50 & $\begin{array}{r}\text { (Grameen } \\
\text { Shakti 2015) }\end{array}$ \\
\hline 2015 & Bangladesh & 50 & $\$ 250.32$ & $\$ 5.01$ & 60 & - & - & - & 1.20 & $\begin{array}{r}\text { (Grameen } \\
\text { Shakti 2015) }\end{array}$ \\
\hline 2015 & Bangladesh & 100 & $\$ 449.29$ & $\$ 4.49$ & 100 & - & - & - & 1.00 & $\begin{array}{r}\text { (Grameen } \\
\text { Shakti 2015) }\end{array}$ \\
\hline 2015 & Bangladesh & 135 & $\$ 500.64$ & $\$ 3.71$ & 130 & - & - & - & 0.96 & $\begin{array}{r}\text { (Grameen } \\
\text { Shakti 2015) }\end{array}$ \\
\hline 2009 & Bangladesh & 50 & $\$ 405.15$ & $\$ 8.10$ & - & - & - & - & - & $\begin{array}{r}\text { (Urmee and } \\
\text { Harries } \\
\text { 2009) }\end{array}$ \\
\hline 2013 & Cambodia & 40 & $\$ 474.30$ & $\$ 11.86$ & 48 & - & - & - & 1.20 & (Pode 2013) \\
\hline 2013 & Cambodia & 78 & $\$ 1,009.80$ & $\$ 12.95$ & 78 & - & - & - & 1.00 & (Pode 2013) \\
\hline 2009 & Cambodia & 40 & $\$ 555.00$ & $\$ 13.88$ & - & - & - & - & - & $\begin{array}{r}\text { (Urmee and } \\
\text { Harries } \\
\text { 2009) }\end{array}$ \\
\hline 2009 & Ethiopia & 10 & $\$ 315.73$ & $\$ 31.57$ & - & - & - & - & - & $\begin{array}{r}\text { (Breyer et al. } \\
2009)\end{array}$ \\
\hline 2009 & Fiji & 100 & $\$ 1,618.38$ & $\$ 16.18$ & - & - & - & - & - & $\begin{array}{r}\text { (Urmee and } \\
\text { Harries } \\
2009)\end{array}$ \\
\hline 2012 & Ghana & 15 & $\$ 404.44$ & $\$ 26.96$ & 12 & - & - & - & - & $\begin{array}{r}\text { (Ghana } \\
\text { Ministry of } \\
\text { Energy } \\
\text { 2012) }\end{array}$ \\
\hline 2012 & Ghana & 50 & $\$ 808.89$ & $\$ 16.18$ & 65 & - & - & - & - & $\begin{array}{r}\text { (Ghana } \\
\text { Ministry of } \\
\text { Energy } \\
2012) \\
\end{array}$ \\
\hline 2012 & Ghana & 100 & $\$ 953.33$ & $\$ 9.53$ & 100 & - & - & - & 1.00 & $\begin{array}{r}\text { (Ghana } \\
\text { Ministry of } \\
\text { Energy } \\
2012) \\
\end{array}$ \\
\hline 2007 & Ghana & 14 & $\$ 609.50$ & $\$ 43.54$ & - & - & - & - & & (Pode 2013) \\
\hline 2007 & Ghana & 100 & $\$ 1,690.50$ & $\$ 16.91$ & - & - & - & - & & (Pode 2013) \\
\hline 2011 & India & 10 & $\$ 71.30$ & $\$ 7.13$ & 7 & - & - & - & 0.70 & $\begin{array}{r}\text { (NABARD } \\
\text { 2011) } \\
\end{array}$ \\
\hline 2011 & India & 50 & $\$ 356.50$ & $\$ 7.13$ & 60 & - & - & - & 1.20 & $\begin{array}{r}\text { (NABARD } \\
\text { 2011) } \\
\end{array}$ \\
\hline 2011 & India & 100 & $\$ 713.00$ & $\$ 7.13$ & 120 & - & - & - & 1.20 & $\begin{array}{r}\text { (NABARD } \\
\text { 2011) } \\
\end{array}$ \\
\hline 2011 & India & 210 & $\$ 1,461.66$ & $\$ 6.96$ & 120 & - & - & - & 0.57 & $\begin{array}{r}\text { (NABARD } \\
\text { 2011) } \\
\end{array}$ \\
\hline 2010 & India & 35 & $\$ 281.90$ & $\$ 8.05$ & 40 & $\$ 56.38$ & $\$ 1.41$ & $20 \%$ & 1.14 & $\begin{array}{r}\text { (Chaurey } \\
\text { and Kandpal } \\
\text { 2010) }\end{array}$ \\
\hline 2010 & India & 70 & $\$ 552.05$ & $\$ 7.89$ & 70 & $\$ 112.76$ & $\$ 1.61$ & $20 \%$ & 1.00 & $\begin{array}{r}\text { (Chaurey } \\
\text { and Kandpal } \\
\text { 2010) }\end{array}$ \\
\hline 2009 & India & 50 & $\$ 549.45$ & $\$ 10.99$ & - & - & - & - & - & $\begin{array}{r}\text { (Urmee and } \\
\text { Harries }\end{array}$ \\
\hline
\end{tabular}




\begin{tabular}{|c|c|c|c|c|c|c|c|c|c|c|}
\hline & & & & & & & & & & 2009) \\
\hline 2012 & Kenya & 40 & $\$ 645.84$ & $\$ 16.15$ & - & - & - & - & - & $\begin{array}{r}\text { (Abdullah } \\
\text { and } \\
\text { Markandya } \\
\text { 2012) }\end{array}$ \\
\hline 2008 & Morocco & 80 & $\$ 1,358.02$ & $\$ 16.98$ & 150 & $\$ 506.41$ & $\$ 3.38$ & $37 \%$ & 1.88 & $\begin{array}{r}\text { (Carrasco et } \\
\text { al. 2013) }\end{array}$ \\
\hline 2009 & Nepal & 30 & $\$ 388.50$ & $\$ 12.95$ & - & - & - & - & - & $\begin{array}{r}\text { (Urmee and } \\
\text { Harries } \\
2009)\end{array}$ \\
\hline 2015 & Nicaragua & 55 & $\$ 600.00$ & $\$ 10.91$ & 107.5 & $\$ 141.00$ & $\$ 1.31$ & $24 \%$ & 1.95 & $\begin{array}{l}\text { (Ranaboldo } \\
\text { et al. 2015) }\end{array}$ \\
\hline 2015 & Nicaragua & 250 & $\$ 2,035.00$ & $\$ 8.14$ & 210 & $\$ 300.00$ & $\$ 1.43$ & $15 \%$ & 0.84 & $\begin{array}{l}\text { (Ranaboldo } \\
\text { et al. 2015) }\end{array}$ \\
\hline 2015 & Nicaragua & 2500 & $\begin{array}{r}\$ 18,268.0 \\
0\end{array}$ & $\$ 7.31$ & 2100 & $\begin{array}{r}\$ 3,000 \\
00\end{array}$ & $\$ 1.43$ & $16 \%$ & 0.84 & $\begin{array}{l}\text { (Ranaboldo } \\
\text { et al. 2015) }\end{array}$ \\
\hline 2009 & Sri Lanka & 50 & $\$ 532.80$ & $\$ 10.66$ & - & - & - & - & - & $\begin{array}{r}\text { (Urmee and } \\
\text { Harries } \\
2009)\end{array}$ \\
\hline 2007 & Tanzania & 14 & $\$ 234.37$ & $\$ 16.74$ & - & - & - & - & - & (Pode 2013) \\
\hline 2007 & Tanzania & 70 & $\$ 965.53$ & $\$ 13.79$ & - & - & - & - & - & (Pode 2013) \\
\hline 2009 & Vietnam & 40 & $\$ 555.00$ & $\$ 13.88$ & - & - & - & - & - & $\begin{array}{r}\text { (Urmee and } \\
\text { Harries } \\
2009)\end{array}$ \\
\hline 2009 & Uganda & 75 & $\$ 1,939.69$ & $\$ 25.86$ & 150 & $\$ 286.42$ & $\$ 1.91$ & $15 \%$ & 2.00 & $\begin{array}{r}\text { (Kyezira et } \\
\text { al. 2009) }\end{array}$ \\
\hline 2009 & Uganda & 14 & $\$ 556.70$ & $\$ 39.76$ & 70 & $\$ 81.06$ & $\$ 1.16$ & $15 \%$ & 5.00 & $\begin{array}{r}\text { (Kyezira et } \\
\text { al. 2009) }\end{array}$ \\
\hline 2011 & Various & 10 & $\$ 212.00$ & $\$ 21.20$ & - & - & - & - & - & (Lysen 2013) \\
\hline
\end{tabular}

Table 1: An overview of reported solar home system costs around the world 


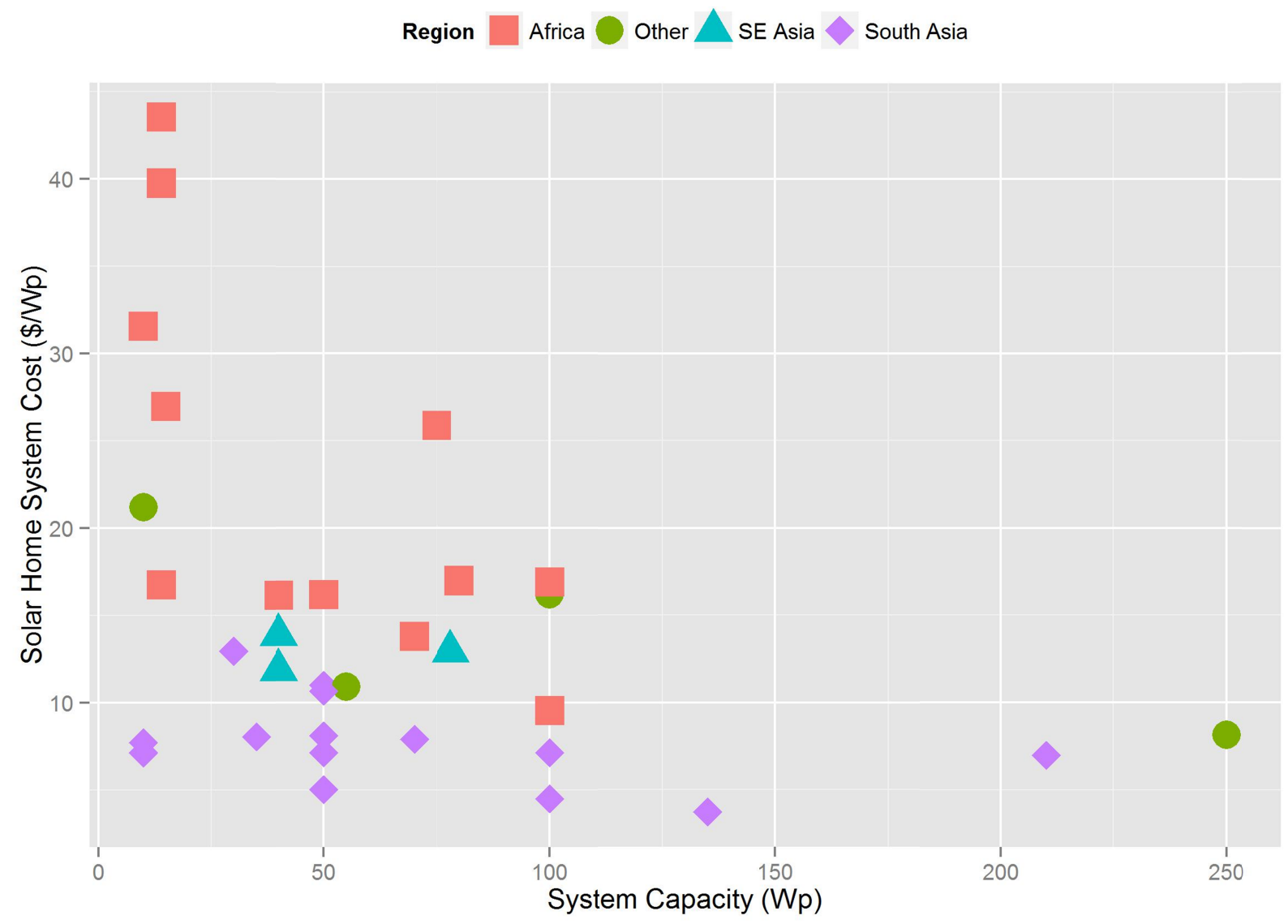

Figure 1: Reported SHS unit costs in several different regions as a function of system capacity. Costs are generally lowest in South Asia, which reflects the relatively maturity of these SHS markets as well as potential direct or indirect subsidization.

\subsection{Grid Expansion Cost Review}

\subsubsection{Transmission and Distribution}

The cost of extending a centralized grid to connect a new structure will depend on a variety of factors, such as the length of the connection, local geography, materials costs, labor costs and many more. Of particularly importance are the line voltage and capacity, which directly and significantly impact the cost of new transmission and distribution infrastructure. A survey in 2000 found that the cost of a "typical" kilometer of grid extension line into rural areas centered around $\$ 9,730$ to $\$ 11,120$, but varied significantly in different countries, from as low as $\$ 3,058$ in India to nearly $\$ 25,020$ in Mali (World Bank 2000). The reported cost reached $\$ 30,580$ in parts of the United States when accounting for the costs of right-of-way clearance, an expense that was not included in most other survey results. These costs cover the voltage and capacity ranges that are typically used for rural electrification in each specific country. It is likely that different countries typically develop lines with different characteristics, which would contribute to the cost differences seen between countries. For example, the low cost in India was primarily attributed to the use of relatively smaller conductors and locally sourced materials. As another example, labor costs account for roughly half the total cost in the U.S. but are in the range of $10 \%$ to $20 \%$ of total costs in developing countries. 
The Energy Technology Systems Analysis Programme of the International Energy Agency has also summarized cost ranges for transmission and distribution infrastructure that have been discussed in other studies (ETSAP 2014). The find costs of roughly $\$ 247,000 / \mathrm{km}$ for both a bipolar high voltage direct current (HVDV) line and a double AC line. They also present cost ranges as a function of line capacity for both long range transmission lines, $\$ 746 / \mathrm{km}-\mathrm{MW}$ to $\$ 3318 / \mathrm{km}-\mathrm{MW}$, and lower voltage distribution lines, $\$ 1491 / \mathrm{km}-\mathrm{MW}$ to $\$ 6636 / \mathrm{km}-\mathrm{MW}$. They also find that investment costs in transmission account for $4 \%$ to $15 \%$ of the total cost of electricity deliver, while investments in distribution account for $27 \%$ to $34 \%$ of the total cost. HVDC converter stations are estimated to cost $\$ 247$ million, while AC substations are estimated to cost $\$ 78$ million, or between $\$ 10,700 / \mathrm{MW}$ and $\$ 24,000 / \mathrm{MW}$. The variation of costs between different countries and geographies is not discussed in detail.

Parshall et al. determined the cost of grid extension in Kenya in 2007 to be $\$ 16,213$ per kilometer for mediumvoltage lines, $\$ 12,203$ per kilometer for low voltage lines, and $\$ 171$ for the fixed cost of connecting each new structure, plus costs for internal household equipment ranging from $\$ 94$ to $\$ 422$ (Parshall et al. 2009). Installed costs for transformers ranged from $\$ 2,591$ for less than $20 \mathrm{~kW}$ to $\$ 6,038$ for up to $80 \mathrm{~kW}$. The authors estimated an average grid connection cost of $\$ 2,185$ per household for a realistic penetration scenario, with the costs for a number of more remote regions exceeding $\$ 4,600$ per household.

Deichmann et al. build upon this analysis, further estimating the cost of higher voltage lines to be $\$ 95,400$ per kilometer for $132 \mathrm{kV}$ and $\$ 203,520$ for $220 \mathrm{kV}$ in Kenya (Deichmann et al. 2011). In a similar analysis of Ghana, Kemausuor et al. assumed costs of $\$ 25,250$ per kilometer for medium-voltage lines, $\$ 12,120$ to $\$ 17,170$ for lowvoltage lines, $\$ 153$ per kW for transformers and $\$ 323$ for equipment and installation per connected household (Kemausuor et al. 2014). This analysis estimated the cost of grid expansion into the relatively remote region of Northern Ghana to be $\$ 2,424$ per household when including initial costs and ten years of recurring costs. Under the assumption that annual recurring costs are $1 \%$ of the total capital cost and are time-discounted, the upfront connection cost is approximately $\$ 2,303$ per household.

An analysis of grid extension in Senegal assumed costs of $\$ 16,640$ per kilometer for medium-voltage lines, $\$ 12,480$ per kilometer for low-voltage lines, $\$ 1,040$ per $\mathrm{kW}$ for transformers and $\$ 274$ per household for connection costs (Sanoh et al. 2012). A case study of Leona, a rural community in Senegal that is the site of a Millennium Village Project, found the cost of grid extension to be approximately $\$ 838$ per household, less than the estimated average cost throughout rural Senegal, which was $\$ 1,090$ (Sanoh et al. 2012).

The costs of grid connection on a per capita basis are also strongly dependent on population density, settlement patterns, and the coverage of existing infrastructure. Nigeria for example is densely populated and already has a widespread transmission network. As a result grid expansion tends to be most cost-effective supply option for those who currently lack electricity access. Ethiopia on the other hand has a number of densely populated urban areas, but the overall population density of the country is lower than that of Nigeria. In addition, existing transmission and distribution infrastructure is less developed and as a result distributed generation technologies may potentially play a more prominent role in future development strategies. This effect is quantified by an analysis presented in the 2014 Africa Energy Outlook, which projects that the electrification rate in Nigeria could increase from $45 \%$ to $85 \%$ by 2040 , whereas the electrification rate in Ethiopia would increase from $23 \%$ to only $60 \%$ under similar assumption (IEA 2015a). Most of the remaining $40 \%$ without access would be located in rural areas. Similar effects are apparent even within single countries. The 2015 India Energy Outlook projected that urban electrification will be essentially universal in India by 2030, however some 60 million people in rural areas will still lack electricity access (IEA 2015a). 


\subsubsection{Generation}

The body of literature estimating the costs of electricity generation from various technologies is far too extensive to review exhaustively here and such costs can vary significantly depending on location and global fuel prices. However we do provide a short review of several relevant studies. Many centralized generation units in the developing world use oil-based products as a fuel source. Such generation is relatively expensive compared to the larger hydroelectric, coal, nuclear, and natural gas combined cycle plants more commonly employed in the developed world, which typically have levelized costs on the order of $\$ 0.08$ to $\$ 0.10$ per kWh (Kost et al. 2013; Salvatore 2013; EIA 2015b). The levelized cost of a small (<50kW) diesel generator has been estimated to be on the order of \$0.17-\$0.21 per kWh, while the levelized cost of a larger (1 to $10 \mathrm{MW})$, utility-scale generator was estimated to be $\$ 0.15-\$ 0.17$ per $\mathrm{kWh}$. These costs are based on a global market price for diesel fuel of $\$ 0.75$ per liter (U.S. Gulf Coast Ultra-Low Sulfur No. 2) (Kost et al. 2013). The cost of providing electricity through a national grid is also highly dependent on both fluctuations in global energy prices and the energy mix of the country; the current trend of low oil prices ( $\$ 0.36$ per liter in November 2015) may reduce these generation costs. However, as natural gas fuel prices are typically correlated with oil prices, it is unlikely that low oil prices will lead to oil-based electricity generation being cheaper than natural gas-based generation. In 2010 the International Energy Agency arrived at a much higher estimate for the levelized cost of electricity from a new diesel combustion turbine in South Africa, approximately $\$ 0.43$ per kWh (IEA and NEA 2010). Alternatively, the Kenyan Ministry of Energy has estimated that centralized generation costs will stabilize around $\$ 0.17$ per kWh by 2018 (Zeyringer et al. 2015).

The average production cost in Africa has also been reported to be $\$ 0.18$ per $\mathrm{kWh}$ as of 2013 (AFDB 2013). A continent-wide modeling analysis of power system expansion in Africa found the cost of new generation in Africa to vary from $\$ 0.13 / \mathrm{kWh}$ in Southern Africa to $\$ 0.37 / \mathrm{kWh}$ in North Africa, with an average of $\$ 0.25 / \mathrm{kWh}$ (Sanoh et al. 2014). One modeling analysis in Kenya assumes LCOEs for various candidate centralized generation projects including, $\$ 0.07 / \mathrm{kWh}$ for geothermal, $\$ 0.10 / \mathrm{kWh}$ for wind and hydro, $\$ 0.11 / \mathrm{kWh}$ for nuclear, $\$ 0.12 / \mathrm{kWh}$ for natural gas and $\$ 0.14 / \mathrm{kWh}$ for coal (Kenya Ministry of Energy 2011), while another in Uganda utilizes a proxy cost of $\$ 0.17 / \mathrm{kWh}$ for electricity from the grid (Murphy et al. 2014). The cost of electricity from a diesel generator was found to vary between $\$ 0.28 / \mathrm{kWh}$ and $\$ 0.33 / \mathrm{kWh}$ depending on capacity, with a diesel cost of $\$ 0.98 / \mathrm{L}$. For compressed natural gas as a fuel source the generation cost varies between $\$ 0.14 / \mathrm{kWh}$ and $\$ 0.16 / \mathrm{kWh}$ at the prevailing cost of $\$ 2.00$ per diesel gallon equivalent (Oladokun and Asemota 2015). Another analysis found the LCOE of an optimized hybrid power system with small diesel generators, storage and solar PV to be $\$ 0.50 / \mathrm{kWh}$ based on a diesel price of $\$ 1.20 / \mathrm{L}$. The LCOE of the optimal hybrid system increases to $\$ 1.60 / \mathrm{kWh}$ for a diesel fuel cost of $\$ 3.00 / L$ (Ouedraogo et al. 2015).

A recent report by the International Energy Agency and the Nuclear Energy Agency provided a limited review of levelized generation costs in three non-OECD countries, China, Brazil, and South Africa (IEA/NEA 2015). In China the LCOE of a combined-cycle natural gas plant was determined to be $\$ 0.095 / \mathrm{kWh}$ at a $7 \%$ discount rate. The LCOE of coal was reported to be $\$ 0.078 / \mathrm{kWh}$ in China and $\$ 0.082 / \mathrm{kWh}$ in South Africa, both with a $7 \%$ discount rate. However, the applicability of these data to the developing world may be limited (Khatib 2016). Another report on the cost of energy generation around the world found there to be an extremely wide range of average LCOE values for hydroelectric generation, $\$ 0.19 / \mathrm{kWh}$ to $\$ 3.14 / \mathrm{kWh}$ for small projects $(<10 \mathrm{MW})$ and $\$ 0.24 / \mathrm{kWh}$ to $\$ 3.02 / \mathrm{kWh}$ for larger projects (WEC/BNEF 2013). It includes limited analysis of the developing world, but does find the LCOE of onshore wind generation to vary between $\$ 0.047 / \mathrm{kWh}$ and $\$ 1.13 / \mathrm{kWh}$ in India, $\$ 0.49 / \mathrm{kWh}$ and $\$ 0.93 / \mathrm{kWh}$ in China, and $\$ 0.55 / \mathrm{kWh}$ and $\$ 0.99 / \mathrm{kWh}$ in Brazil. A study specific to sub-Saharan Africa projected the LCOE of several centralized generation technologies in various countries in 2020 (Castellano et al. 2015). It estimates the LCOE of natural gas to range from $\$ 0.047 / \mathrm{kWh}$ to $\$ 0.065 / \mathrm{kWh}$, with the disclaimer that natural gas may not be widely available as a fuel source in all countries. The LCOE of coal is projected to be between $\$ 0.059 / \mathrm{kWh}$ and 
$\$ 0.071 / \mathrm{kWh}$ in the three countries with $94 \%$ of the coal resource capacity in the region, South Africa, Botswana, and Mozambique. Throughout the rest of the region the cost is projected to fall between $\$ 0.073 / \mathrm{kWh}$ and $\$ 0.086 / \mathrm{kWh}$. Large-scale wind generation in countries with high wind speeds was found to have an LCOE between $\$ 0.107 / \mathrm{kWh}$ and $\$ 0.142 / \mathrm{kWh}$. The LCOE of hydro can vary significantly depending on location, between $\$ 0.059 / \mathrm{kWh}$ and $\$ 0.083 / \mathrm{kWh}$ in East Africa and more than $\$ 0.13 / \mathrm{kWh}$ in West Africa. Proposed generation facilities at Inga Falls in the Democratic Republic of Congo (DRC) - discussed further below - have been projected to have a LCOE as low as $\$ 0.025 / \mathrm{kWh}$.

The International Renewable Energy Agency developed a systems planning model that has been utilized to develop long term infrastructure development plans for West Africa and Southern Africa (IRENA 2013a, 2013b). These analyses include levelized cost assumptions for a number of different generation technologies. The values that follow are the same for both regions and exclude all transmission and distribution costs. The levelized cost of diesel generation is assumed to be $\$ 0.291 / \mathrm{kWh}$ for large, centralized generators and $\$ 0.604 / \mathrm{kWh}$ for small, distributed generators $(<1 \mathrm{~kW})$. Open-cycle natural gas turbines with a domestic fuel supply are assumed to have a levelized cost of $\$ 0.141 / \mathrm{kWh}$ and natural gas combined-cycle units, a levelized cost of $\$ 0.090 / \mathrm{kWh}$. The levelized costs of utility scale solar and bulk wind generation with a 30\% capacity factor are $\$ 0.121 / \mathrm{kWh}$ and $\$ 0.102 / \mathrm{kWh}$ respectively, and of large and small hydro, $\$ 0.062 / \mathrm{kWh}$ and $\$ 0.107 / \mathrm{kWh}$ respectively.

The Democratic Republic of Congo has roughly half of the all the hydroelectric potential in sub-Saharan Africa, including the massive resource at Inga Falls (Castellano et al. 2015). There are currently two generation units in operation at Inga Falls. The 351 MW Inga I unit was completed in 1972 and the 1,424 MW Inga II was completed in 1982. However, utilization of both of these units is currently relatively low due to poor maintenance and political instability. A third unit, Inga III, with 4,755 MW of capacity has been proposed and construction is set to commence in the near future (Taliotis et al. 2014). A series of additional units have also been discussed, which would bring the total generation capacity of the site to $42 \mathrm{GW}$, roughly equal to the current generation capacity of all of sub-Saharan Africa (excluding South Africa). One modeling analysis found that the large hydro resources at Grand Inga and throughout Central Africa can be exported to anywhere in Africa for a delivered cost of no more than $\$ 0.20 / \mathrm{kWh}$, including $\$ 0.13 / \mathrm{kWh}$ in Egypt and $\$ 0.09 / \mathrm{kWh}$ in South Africa (Sanoh et al. 2014).

It is clear that centralized generation costs are highly variable depending on a variety of factors including fuel mix and resource availability. We assume a baseline centralized generation cost of $\$ 0.10$ per $\mathrm{kWh}$ to roughly represent a system where baseload electricity is provided by natural gas or coal, with costs potentially offset in either direction by lower cost large hydro generation, or higher cost diesel generation for peaking. We do not wish to imply that this is cost assumption can be universally applied throughout the developing world. In many developing countries where there is more reliance on diesel generators, average costs may be somewhat higher, while in those countries with abundant natural gas, coal or hydro resources average costs may be somewhat lower. We therefore also consider two sensitivity scenarios with average generation costs of $\$ 0.05 / \mathrm{kWh}$ and $\$ 0.25 / \mathrm{kWh}$ to reflect potential variations in this important input parameter.

\subsection{Methodology}

We now present an analysis that considers the true cost of energy service provision, as a function of the capital costs of a SHS and grid connection, rather than assuming fixed, subsidized grid tariffs. This methodology is then used to analyze the choice between pursuing grid expansion and investment in distributed SHSs. Specifically we determine the "breakeven electricity consumption level" for a given SHS capital cost and grid connection cost, at which point the cost of delivering electricity through each approach is equivalent. Therefore, all else equal, the centralized approach would be more cost-effective for greater consumption levels and the distributed approach 
would be more cost-effective for lower consumption levels. Due to the previously outlined variation in costs for both SHS and grid expansion in different regions on the world, we frame our analysis to explore the full range of potential values across both these parameter dimensions. This provides a more general framework for understanding the choice between pursuing distributed versus centralized electrification strategies across regions and cost scenarios.

\subsubsection{True cost of electricity from the grid}

The true cost of electricity provision through the grid is calculated as a function of the per structure grid connection cost, based on the fixed parameters shown in Table 2. This cost of provision can be broken into two components, the fixed cost of the transmission, distribution, and substation investments that are required to extend the grid, and the levelized cost of generation for each unit of electricity that is provided. The fixed cost is calculated as a function of the per structure grid connection cost as follows.

\begin{tabular}{|l|r|r|}
\hline Parameter & Value & \multicolumn{1}{l|}{ Symbol } \\
\hline Grid Connection Cost (\$/structure) & - & $C_{g}$ \\
\hline Loan Term (years) & 30 & $N_{g}$ \\
\hline Interest Rate & $10 \%$ & $i_{g}$ \\
\hline Discount Rate & $5 \%$ & $r_{g}$ \\
\hline Annual Maintenance $(\%$ of capital cost) & $1 \%$ & $m_{g}$ \\
\hline Lifetime (years) & 50 & $T_{g}$ \\
\hline Levelized Cost of Centralized Generation(\$/kWh) & 0.10 & $c$ \\
\hline
\end{tabular}

Table 2: Grid Cost Parameters. These parameters are original input assumptions based upon a review of multiple different sources. These values were chosen to be broadly applicable across a range of scenarios. Actual values will vary depending on the specific technology and geographic location being considered, as well as a range of other project-specific factors. Therefore, all results that follow should be considered in the context of all input assumptions.

To annualize the fixed cost of grid extension, an annual capital payment $(p)$ first is calculated for a given grid connection cost using a standard fixed-payment amortization formula.

$$
p_{g}=i_{g} \cdot \frac{C_{g}}{1-\left(1+i_{g}\right)^{-N_{g}}}
$$

These payments are assumed to occur annually over the loan term, while maintenance costs are assumed to occur over the entire lifetime of the system. Equation (2) therefore represents the present value of the time-discounted cost stream of grid expansion, assuming that the system lifetime is longer than the loan term.

$$
P V_{g}=\sum_{t=1}^{N_{g}} \frac{p_{g}+m_{g}}{\left(1+r_{g}\right)^{t}}+\sum_{t=N_{g}+1}^{T_{g}} \frac{m_{g}}{\left(1+r_{g}\right)^{t}}
$$


The annualized cost of grid connection is the quantity $\left(x_{g}\right)$ that satisfies equation (3). This can alternatively be thought of as the cost that when applied during each year of the lifetime of the transmission system will have a present value equal to the present value of the original time-discounted cost stream.

$$
P V_{g}=\sum_{t=1}^{T_{g}} \frac{x_{g}}{\left(1+r_{g}\right)^{t}}
$$

Solving for $x_{g}$ yields

$$
x_{g}=\frac{P V_{g}}{\sum_{t=1}^{T_{g}}\left(1+r_{g}\right)^{-t}}
$$

This is similar to a levelized cost of electricity calculation, except here the costs are levelized over a number of years of grid operation, as opposed to a number of kilowatt-hours of electricity generation. The annualized cost $\left(A C_{g}\right)$ of energy provision through the grid is therefore this fixed cost plus the variable cost of generation multiplied by the annual energy consumption level ( $y$ ).

$$
A C_{g}=x_{g}+c \cdot y
$$

\subsubsection{True cost of electricity from a solar home system}

The true cost of electricity from a SHS is similarly calculated as a function of the unit capital cost of the system, in dollars per $\mathrm{Wp}$. This cost is then combined with ongoing maintenance and battery replacement costs and levelized over the lifetime electricity generation of the system to arrive at a levelized cost of generation as follows.

\begin{tabular}{|l|r|r|}
\hline Parameter & Value & \multicolumn{1}{|c|}{ Symbol } \\
\hline Capital per Wp & - & $C_{s}$ \\
\hline Interest Rate & $20 \%$ & $I_{s}$ \\
\hline Loan Term (years) & 5 & $N_{s}$ \\
\hline Discount Rate & $5 \%$ & $R_{s}$ \\
\hline Annualized Battery Replacement Cost ${ }^{3}$ & $4 \%$ of capital/year & $b$ \\
\hline Battery Replacement Frequency (years) & 5 & - \\
\hline Lifetime (years) & 20 & $T_{s}$ \\
\hline Annual Maintenance (\% of capital cost) & $1 \%$ & $M_{s}$ \\
\hline Capacity Factor & $20 \%$ & - \\
\hline
\end{tabular}

Table 3: SHS Cost Parameters. These parameters are original input assumptions based upon a review of multiple different sources. Actual values will vary depending on the specific technology and geographic location being considered. Battery cost assumptions are for lead-acid batteries, which are currently more commonly used in SHS

\footnotetext{
${ }^{3}$ Assumes that the battery is replaced every five years for $20 \%$ of the total system cost
} 
applications due to lower costs. However, cost reduction for lithium-ion batteries may alter this dynamic the future.

The methodology for calculating this levelized cost is similar to the method presented above for grid expansion, although many key parameters differ. For example, loans for an individual SHS would typically have higher interest rates and shorter terms than those made available to utilities and governments for large capital investments in grid expansion. The parameter assumptions presented in Table 3 reflect this assumption. However, as previously discussed, it is also possible for governments to take a centralized approach to implementing distributed energy systems, in which case more favorable financing terms may be available. This possibility will be analyzed in more detail later.

An annual loan repayment amount $\left(p_{s}\right)$ is calculated according to a standard fixed-payment amortization formula.

$$
p_{s}=i_{s} \cdot \frac{C_{s}}{1-\left(1-i_{s}\right)^{-N_{s}}}
$$

Similar to the grid calculation, a cost stream that includes maintenance and battery replacements can then be constructed. The present value of this cost stream is calculated as in equation (7).

$$
P V_{s}=\sum_{t=1}^{N_{s}} \frac{p_{s}+m_{s}+b}{\left(1+r_{s}\right)^{t}}+\sum_{t=N_{S}+1}^{T_{s}} \frac{m_{s}+b}{\left(1+r_{s}\right)^{t}}
$$

A SHS may also be provided through a rental program or other similar arrangements, where a regular payment is made in exchange for use of the SHS, potentially including maintenance and battery replacement. While the following analysis will focus on a loan-based model, equation (7) could easily be adjusted to represent a different monthly or annual cost stream. For a more detailed analysis and discussion of different financing mechanisms that may be used see Levin and Thomas (2014b).

The levelized cost of a SHS is the quantity $\left(L_{s}\right)$ that satisfies the following relation, where $z$ is the annual quantity of electricity generated by the system. This can similarly be thought of as the cost that when applied to each unit of generation will have a present value equal to the present value of the original time-discounted cost stream $\left(P V_{s}\right)$.

$$
\begin{gathered}
P V_{s}=\sum_{t=1}^{T_{s}} \frac{L_{s} \cdot z}{\left(1+r_{s}\right)^{t}} \\
L_{s}=\frac{P V_{s}}{Z \cdot \sum_{t=1}^{T_{s}}\left(1+r_{s}\right)^{-t}}
\end{gathered}
$$

The annualized cost (ACS) of energy provision through a SHS is therefore simply this levelized cost multiplied by the annual energy consumption level $(y)$.

$$
A C_{s}=L_{s} \cdot y
$$




\subsubsection{Breakeven Energy Consumption}

Grid expansion requires a fixed upfront investment in transmission and distribution infrastructure, but typically has the benefit of a lower levelized cost for each unit of generation. Therefore, broadly speaking, grid expansion is more cost-effective when energy consumption is high and a SHS is more cost-effective when energy consumption is low. This tradeoff can be directly compared to determine a breakeven energy consumption level, at which the cost of energy provision through both grid expansion and a SHS is the same. This approach has also been used in conjunction with a network expansion algorithm to identify priority locations for distributed generation infrastructure (Levin and Thomas 2012). Therefore, if actual energy consumption is less than this amount, a SHS would be the cheaper option whereas if actual energy consumption is greater that this amount, grid expansion would be cheaper. Equation (11) equates the costs of energy provision from each approach as defined in equations (5) and (10), with $Y$ being the breakeven annual energy consumption level.

$$
x_{g}+c \cdot Y=L_{s} \cdot Y
$$

Solving for $Y$ yields,

$$
Y=\frac{x_{g}}{L_{S}-c}
$$

As the cost of grid expansion $\left(x_{g}\right)$ increases the breakeven energy consumption level also increases, while the opposite holds for increasing SHS costs. If the levelized cost of electricity from a SHS $\left(L_{S}\right)$ is less than the levelized generation cost of a centralized plant $(c)$, then the breakeven energy consumption level becomes negative, implying that it would never be cost-effective to pursue a centralized electrification strategy.

\section{Results and discussion}

We now apply the parameter assumptions outlined in Tables 2 and 3 and cost data for several different regions to demonstrate a potential application of this analytical framework.

When all other parameters are held constant, $x_{g}$ becomes a simple linear function of the per structure grid connection cost $\left(C_{g}\right)$. Applying the values presented in Table 3 yields the following relation, where $C_{g}$ is in dollars per structure and $x_{g}$ is in dollars per year.

$$
x_{g}=.099 \cdot C_{g}
$$

Similarly, when all other parameters are held constant, $L_{s}$ becomes a simple linear function of the unit capital cost of the SHS $\left(C_{s}\right)$. Applying the values presented in Table 3 yields the following relation, where $L_{s}$ is in dollars per kWh and $C_{s}$ is in dollars per Wp.

Equation (12) thus becomes,

$$
L_{s}=.093 \cdot C_{s}
$$

$$
Y=\frac{.099 \cdot C_{g}}{.093 \cdot C_{s}-.10}
$$


Under these parameter assumptions we now analyze three specific regions that were discussed in section 2.2: Leona, Senegal, Northern Ghana, and rural Kenya. These regions are assumed to have per structure grid connection costs of $\$ 838, \$ 2302$, and $\$ 4600$ respectively.

The SE4All Global Tracking Framework established a multi-tier methodology for measuring energy access. While the Framework clearly states that a simplified electricity consumption metric does not fully encapsulate the level of energy access available to a given household, an effort was made to convert each of the five access tiers into a consumption range. These energy services available in each access tier and the associated minimum annual household electricity consumption level are outlined in Table 4. These consumption ranges were established in the second edition of the Framework (IEA and World Bank 2015), and differ slightly from those outlined in the first edition (Angelou et al. 2013).

Figure 2 shows the breakeven annual energy consumption level for each region as a function of the unit capital cost of a SHS. This metric provides a means for comparing the relative cost-effectiveness of SHS deployment and grid expansion for various SHS costs and annual consumption levels. In regions to the right of each line grid expansion is the cheaper option, while for regions to the left of each line a SHS would be the cheaper option. For example, in the case of Northern Ghana, a SHS with a $\$ 6 / \mathrm{Wp}$ capital cost would be the cheaper option for electricity provision when annual consumption is less than about $500 \mathrm{kWh}$ per structure per year. The breakeven consumption level with a $\$ 6 / \mathrm{Wp}$ capita cost is about $1,000 \mathrm{kWh} /$ year in Rural Kenya. Alternatively, if annual consumption in Lenoa, Senegal is $500 \mathrm{kWh} / \mathrm{year}$, a grid connection would be the cheaper option as long as SHS capital costs exceed $\$ 3 / \mathrm{Wp}$.

The annual energy consumption levels that correspond with reaching each tier of energy access as defined by the SE4All framework - listed in Table 4 - are also indicated in the figure. It is therefore possible to identify the SHS capital cost that enables each access tier to be reached through electricity provision from a SHS. These capital cost values are listed in Table 5 for baseline assumptions (which is represented graphically in Figure 2), as well as for three sensitivity scenarios.

\begin{tabular}{|l|r|r|}
\hline & $\begin{array}{l}\text { Annual Energy } \\
\text { Consumption (kWh per } \\
\text { household) }\end{array}$ & Indicative Electricity Services \\
\hline Tier 1 & 4.5 & Task lighting and phone charging \\
\hline Tier 2 & 73 & General lighting, television, and fan (if needed) \\
\hline Tier 3 & 365 & Tier 2 and medium power appliances \\
\hline Tier 4 & 1250 & Tier 3 and high power appliances \\
\hline Tier 5 & 3000 & Tier 4 and very high power appliances \\
\hline
\end{tabular}

Table 4: Annual electricity consumption levels corresponding to each of five tiers of energy access, as defined by the United Nations Sustainable Energy for All initiative (IEA and World Bank 2015) 


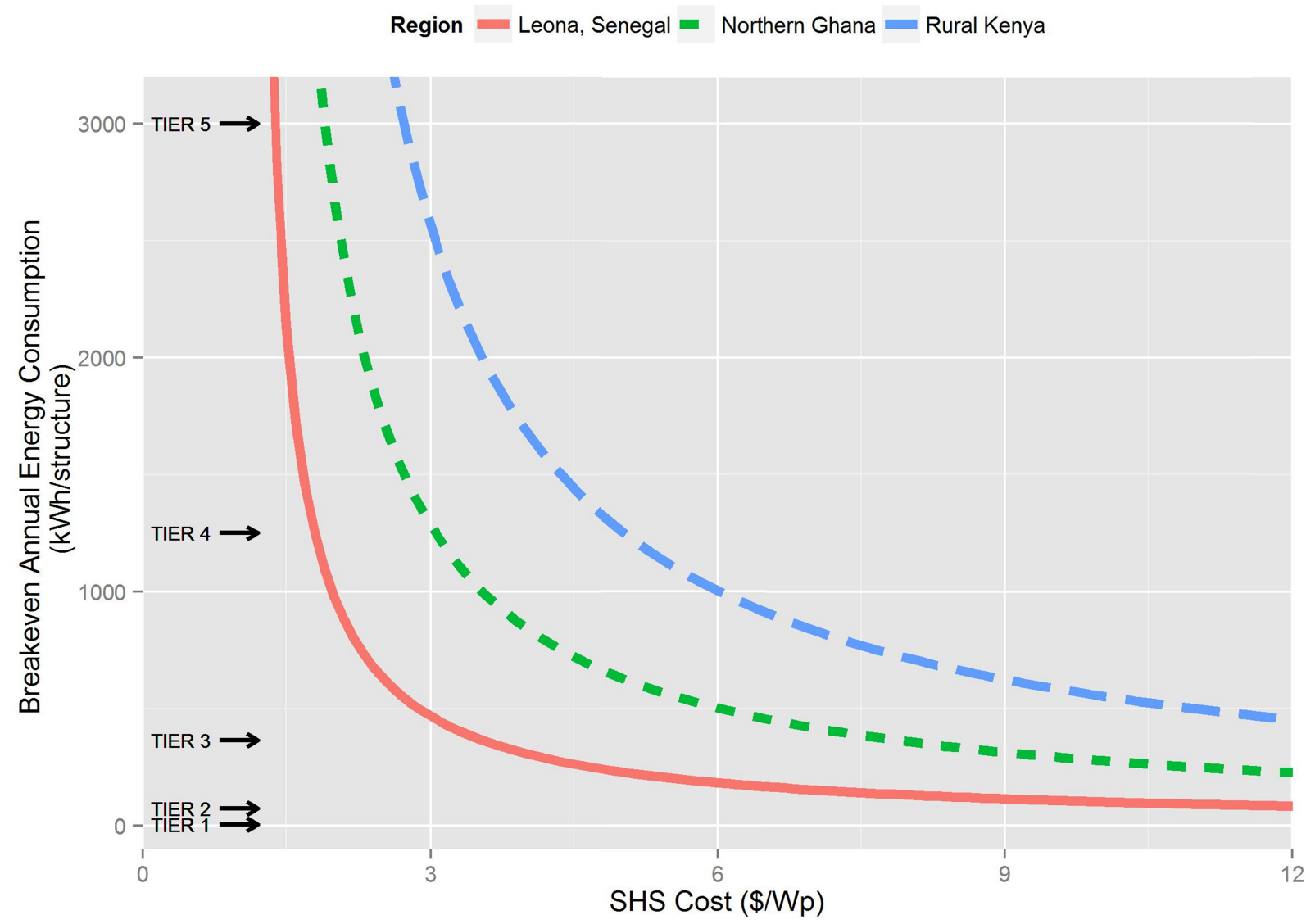

Figure 2: Breakeven annual electricity consumption as a function of SHS capital cost for the three regions discussed in section 2.2. Electricity provision through the grid would be the cheaper option for consumption levels greater than the breakeven quantity, while provision through a SHS would be the cheaper option for lower consumption levels. These baseline results are also summarized in Table 1.

Under baseline assumptions it is clear that SHS deployment is a lower-cost option than grid extension to achieve Tier 1 energy access in all three considered regions, and likely for Tier 2 access as well. Northern Ghana could potentially achieve Tier 3 access with SHS deployment if capital costs could be reduced to less than $\$ 7.84$ per Wp; these costs are currently found in India, Bangladesh and other more mature SHS markets. Rural Kenya could achieve Tier 4 access with SHS deployment if costs were to reach $\$ 5.02$ per Wp. This cost level has been achieved for larger systems in Bangladesh and is perhaps a reasonable short to medium term target for Kenya as technologies continue to develop and markets mature. The provision of Tier 5 energy access solely through SHS deployment is not cost-effective in any of these regions given current conditions; however it is certainly conceivable that SHS capital costs on the order of $\$ 2.00-\$ 3.00$ per Wp could be achieved over the next decade given current SHS cost reduction trends around the world.

This baseline analysis assumes that each SHS is financed directly by the end consumer at a relatively high interest rate of $20 \%$. However, as discussed in section 3.2, utilities and governments can also take an institutionally centralized approach to the development of distributed technologies. In this case, interest rates and other financing terms would likely be more favorable. Table 5 also shows a sensitivity analysis where we assume that SHSs are financed at $10 \%$ interest rate that is also applied to grid development. This causes SHS deployment to be 
the lower-cost electrification option even when capital costs are somewhat higher; Tier 3 access could be achieved in Northern Ghana with SHSs when costs are less than $\$ 9.24$ per Wp and Tier 4 access in Rural Kenya could be achieved when costs are less than $\$ 5.92$ per Wp. We also consider sensitivities around the levelized cost of electricity from the grid. The baseline assumption of $\$ 0.10$ is based upon a presumed mix of lower cost hydro or natural gas generation along with diesel generation during peak load periods, as may be common in many developing countries. However, in some regions the centralized power system may be far more reliant on diesel generators for electricity generation, in which case the average levelized cost of electricity would be somewhat greater. Alternatively, some regions may have access to more abundant hydroelectric resources, reducing their average levelized cost of electricity. The impacts of these sensitivity assumptions are also shown in Table 5 . A change in the levelized cost of centralized generation does not greatly impact the relative cost-effectiveness of SHS deployment of Tier 1 and Tier 2 access levels. This is because an overwhelming majority of the total costs of electrification and consumption are related to infrastructure investments when annual consumption is low. When the levelized cost of centralized generation is $\$ 0.25 / \mathrm{kWh}$, SHS deployment becomes cost-effective for Tier 3 consumption level in Ghana for costs up to $\$ 9.46 / \mathrm{Wp}$, and in Leona, Senegal for costs up to $\$ 5.16 / \mathrm{Wp}$. Tier 5 consumption becomes cost-effective in Rural Ghana for an SHS cost of \$4.34 or less, which is comparable to the current cost of larger systems in Bangladesh. For a levelized cost of centralized generation cost $\$ 0.05 / \mathrm{kWh}$, Tier 3 consumption levels can be cost-effectively served by SHS deployment if capital costs are less than $\$ 7.30$ in Northern Ghana, and \$14.05 in Rural Kenya.

\begin{tabular}{|c|c|c|c|c|}
\hline \multirow{2}{*}{\multicolumn{2}{|c|}{ Baseline }} & Leona, Senegal & Northern Ghana & Rural Kenya \\
\hline & & \multicolumn{3}{|c|}{$\begin{array}{l}\text { SHS deployment is more cost-effective than centralized } \\
\text { generation when the capital cost of a SHS }(\$ / \mathrm{Wp}) \text { is less } \\
\text { than the value shown. }\end{array}$} \\
\hline \multirow[t]{5}{*}{ Electricity consumption: } & Tier 1 & $\$ 200.67$ & $\$ 549.59$ & $\$ 1,096.68$ \\
\hline & Tier 2 & $\$ 13.38$ & $\$ 34.89$ & $\$ 68.62$ \\
\hline & Tier 3 & $\$ 3.54$ & $\$ 7.84$ & $\$ 14.59$ \\
\hline & Tier 4 & $\$ 1.80$ & $\$ 3.05$ & $\$ 5.02$ \\
\hline & Tier 5 & $\$ 1.38$ & $\$ 1.90$ & $\$ 2.72$ \\
\hline \multicolumn{5}{|l|}{$10 \%$ SHS Interest } \\
\hline & Tier 1 & $\$ 236.37$ & $\$ 647.36$ & $\$ 1,291.77$ \\
\hline & Tier 2 & $\$ 15.76$ & $\$ 41.10$ & $\$ 80.82$ \\
\hline & Tier 3 & $\$ 4.17$ & $\$ 9.24$ & $\$ 17.18$ \\
\hline & Tier 4 & $\$ 2.12$ & $\$ 3.60$ & $\$ 5.92$ \\
\hline & Tier 5 & $\$ 1.62$ & $\$ 2.24$ & $\$ 3.21$ \\
\hline \multicolumn{5}{|l|}{$\$ 0.25 / \mathrm{kWh}$ Centralized } \\
\hline & Tier 1 & $\$ 202.29$ & $\$ 551.21$ & $\$ 1,098.30$ \\
\hline & Tier 2 & $\$ 15.00$ & $\$ 36.51$ & $\$ 70.23$ \\
\hline & Tier 3 & $\$ 5.16$ & $\$ 9.46$ & $\$ 16.21$ \\
\hline & Tier 4 & $\$ 3.42$ & $\$ 4.67$ & $\$ 6.64$ \\
\hline & Tier 5 & $\$ 3.00$ & $\$ 3.52$ & $\$ 4.34$ \\
\hline \multicolumn{5}{|l|}{$\$ 0.05 / \mathrm{kWh}$ Centralized } \\
\hline & Tier 1 & $\$ 200.13$ & $\$ 549.05$ & $\$ 1,096.14$ \\
\hline & Tier 2 & $\$ 12.84$ & $\$ 34.35$ & $\$ 68.08$ \\
\hline & Tier 3 & $\$ 3.00$ & $\$ 7.30$ & $\$ 14.05$ \\
\hline
\end{tabular}




\begin{tabular}{l|lll} 
Tier 4 & $\$ 1.26$ & $\$ 2.51$ & $\$ 4.48$ \\
Tier 5 & $\$ 0.84$ & $\$ 1.36$ & $\$ 2.18$
\end{tabular}

Table 5: The SHS capital cost that is required to provide each SE4All energy access tier at lower cost than a grid connection is shown under baseline assumptions, as well as for three sensitivity scenarios. A high cost implies more favorable conditions for SHS deployment, while a low cost implies more favorable conditions for grid expansion. This is because the listed cost represents the cost at which a consumer would be financially indifferent between obtaining a SHS or a grid connection. Therefore a high value means that a SHS is the overall least-cost option even when the SHS itself is relatively expensive.

\section{Conclusions}

Over the past century, the concept of universal electrification has been synonymous with universal access to a grid connection. Distributed energy systems have largely existed to complement this centralized framework. The emergence of lower cost distributed technologies has created a fundamental shift in how energy services are being consumed, and a comprehensive national scale grid is no longer a necessary condition of universal access in a country or region.

Comprehensive energy planning should consider long time horizons over which cost parameters will likely change. The decision to extend the grid requires significant upfront investment that may commit a region to a centralized electricity delivery mechanism for years or decades to come. Distributed approaches may be implemented more gradually, scaling as demand increases and reacting to potential future cost reductions. It is clear that distributed SHSs can play an important role in achieving the SE4All goal of universal access to modern energy systems by providing populations in currently un-electrified regions with Tier 1 or Tier 2 access. However, it is also often argued that while a SHS may be cost-effective for small consumption levels, as consumers gain access to electricity for the first time their demand will increase, eventually to the point where grid extension would have been more cost-effective. Therefore the long planning horizons and large upfront costs of grid expansion are often justified in part by the argument that such infrastructure is necessary to support demand growth over time. In the current economic paradigm, centralized systems are still a vital component of the transition up the energy ladder to Tier 4 and Tier 5 access levels. Localized mini-grids powered by wind, solar or small hydroelectric generators may also become an increasingly attractive alternative that combines elements of purely centralized or decentralized development plans, i.e. shorter implementation time than a comprehensive national scale centralized generation and transmission system (but longer than an individual SHS) and lower generation costs than a SHS (but potentially greater than those from a large centralized unit).

Yet, the costs of distributed generation technologies have experienced dramatic reductions in in recent years and this trend shows no signs of abating. Rooftop solar systems (without storage) are approaching grid parity in parts of the developed world, and the large majority of distributed installations are taking place on structures that are already connected to the grid (i.e. have zero grid connection cost). The cost of large, utility-scale wind and solar generation has also decreased rapidly in recent years, and additional future cost reductions can likely be expected. At the same time, the costs of traditional centralized generation facilities, such as nuclear, coal, natural gas and hydro, as well as transmission infrastructure have remained relatively constant over recent decades. As demand for distributed systems increases, markets will mature and larger systems will be installed. Both of these effects should drive economies of scale to help reduce the average system cost on a per unit (dollars per Wp) basis. Alternatively, as currently un-electrified regions receive access to electricity for the first time, it is reasonable to expect that their demand for energy services will continue to grow, making centralized systems more attractive. 
System planners must balance the tradeoff between these two effects when planning the development of power infrastructure that may be in operation for decades to come as costs and demands continue evolve and fluctuate over time.

Batteries represent a significant portion of the total cost of a SHS, but energy storage also provides additional services that are not inherently available through a grid connection. While energy storage is an essential component of a SHS, due to the intermittent nature of solar illumination, energy storage is not strictly necessary for those who consume electricity through a grid connection. However, energy storage provides additional tangible value for grid-connected consumers. Many consumers with a grid connection in unreliable regions also choose to maintain energy storage or backup diesel generators to provide service during power outages. When a direct economic comparison is made this additional cost is generally attributed to a SHS which includes storage, but it is not usually factored into the costs of consuming electricity through the grid. Additionally, a SHS is typically sold as part of a package that includes appliances that consumers would otherwise have to purchase separately for their grid-connected home or business.

Centralized electrification strategies based on grid-expansion may still be the optimal means of providing energy services throughout much of the world (Levin and Thomas 2012). However, there are cases where a distributed approach is justified for economic, social or geopolitical reasons. For example, national-scale electric grids require massive, concentrated capital investments that must be coordinated through a centralized entity and implemented over years or even decades. This is a challenging proposition under the best of circumstances and the lack of long-term institutional stability in parts of the developing world only serves to increase the challenge. Distributed technologies can be disseminated on regional or local scales much more quickly and require less centralized coordination. This increased speed of implementation may generate significant socio-economic benefits for populations that will otherwise continue to lack affordable and reliable access to basic energy services. Many consumers may be willing to pay a premium for the earlier access, increased reliability, autonomy and environmental benefits that are afforded by a SHS compared to electricity provided through a centralized grid. Moreover, the implementation of distributed electricity services outside of the centralized utility business model could provide opportunities for innovation in the development of electricity service business models, energy efficient direct current appliances and energy storage approaches. However, it can also be difficult for individual consumers to gain access to the capital required for a SHS purchase. Therefore innovative business and financing models are also needed to support technology adoption (Palit and Chaurey 2011; Bhattacharyya 2013; Levin and Thomas 2014b). While not directly considered in our analysis, localized micro-grids powered by solar arrays, wind turbines or small hydroelectric generators may also offer a promising hybrid approach to achieving energy access goals in an efficient and cost-effective manner.

Distributed approaches to electrification are increasingly receiving institutional support from governments and aid agencies in the form of direct subsidies or programmatic support. However, this support still often falls short of what is available for the development and operation of a centralized electrification system and distributed electrification programs may be operated independently of grid expansion efforts, rather than as a single coordinated program (Palit and Chaurey 2011; van Els et al. 2012; Martin and Susanto 2014; Urpelainen 2014). Many rural consumers pay grid tariffs that are well below cost-recovery for those regions, and as a result are implicitly subsidized directly by their government or utility, or cross-subsidized by consumers in urban areas. An integrated approach to new power infrastructure development with commensurate levels of financial and institutional support for distributed approaches to energy service provision, could propel developing countries to become leaders in next-generation energy technologies. 


\section{Acknowledgement}

This work was supported in part by the National Science Foundation through a Graduate Research Fellowship to Todd Levin. 


\section{References}

AFDB. The High Cost of Electricity Generation in Africa [Internet]. Abidjan, Côte d'Ivoire: The African Development Bank Group; 2013 Feb. Available from: http://www.afdb.org/en/blogs/afdb-championing-inclusivegrowth-across-africa/post/the-high-cost-of-electricity-generation-in-africa-11496/

Angelou N, Bhatia M. Capturing the multi-dimensionality of energy access [Internet]. Washington, DC: World Bank Group; 2014. Report No.: 2014/16. Available from:

http://documents.worldbank.org/curated/en/2014/06/19670596/capturing-multi-dimensionality-energyaccess

Angelou N, Elizondo Azuela G, Banerjee SG, Bhatia M, Bushueva I, Inon JG, et al. Global tracking framework. Sustainable energy for all [Internet]. Washington, DC: The World Bank; 2013. Available from: http://documents.worldbank.org/curated/en/2013/05/17765643/global-tracking-framework-vol-3-3main-report

Bhattacharyya SC. Financing energy access and off-grid electrification: A review of status, options and challenges. Renewable and Sustainable Energy Reviews. 2013 Apr;20(0):462-72.

Castellano A, Kendall A, Nikomarov M, Swemmer T. Brighter Africa: The growth potential of the sub-Saharan electricity sector [Internet]. McKinsey and Company; 2015 Feb. Available from: http://www.mckinsey.com/insights/energy_resources_materials/powering_africa

Deichmann U, Meisner C, Murray S, Wheeler D. The economics of renewable energy expansion in rural SubSaharan Africa. Energy Policy. 2011 Jan;39(1):215-27.

EIA. Electric Power Monthly: May 2015 [Internet]. Washington, DC: Energy Information Administration; 2015a. Available from: http://www.eia.gov/electricity/monthly/

EIA. Levelized Cost and Levelized Avoided Cost of New Generation Resources in the Annual Energy Outlook 2015 [Internet]. Washington, DC: Energy Information Administration; 2015b Jun. Available from: http://www.eia.gov/forecasts/aeo/electricity_generation.cfm

Ela E, Milligan M, Bloom A, Botterud A, Townsend A, Levin T. Evolution of Wholesale Electricity Market Design with Increasing Levels of Renewable Generation [Internet]. National Renewable Energy Laboratory; 2014 Sep. Report No.: NREL/TP - 5D00 - 61765. Available from: http://www.nrel.gov/docs/fy14osti/61765.pdf

van Els RH, de Souza Vianna JN, Brasil Jr. ACP. The Brazilian experience of rural electrification in the Amazon with decentralized generation - The need to change the paradigm from electrification to development. Renewable and Sustainable Energy Reviews. 2012 Apr;16(3):1450-61.

ETSAP. Electricity Transmission and Distribution [Internet]. Paris, France: International Energy Agency: Energy Technology Systems Analysis Program; 2014 Apr. Report No.: E12. Available from: http://www.ieaetsap.org/Energy_Technologies/Energy_Supply.asp

Gomez MF, Silveira S. Rural electrification of the Brazilian Amazon - Achievements and lessons. Energy Policy. 2010 Oct;38(10):6251-60.

Gómez MF, Silveira S. The last mile in the Brazilian Amazon - A potential pathway for universal electricity access. Energy Policy. 2015 Jul;82:23-37.

Grameen Shakti. Grameen Shakti Solar Home System Price List [Internet]. 2015. Available from: http://www.gshakti.org/index.php?option=com_content\&view=article\&id=115\&ltemid=124 
IEA. World Energy Outlook 2014 [Internet]. Paris, France: International Energy Agency; 2014b. Available from: http://www.worldenergyoutlook.org/

IEA. India Energy Outlook [Internet]. Paris, France: International Energy Agency; 2015a. Available from: https://www.iea.org/publications/freepublications/publication/india-energy-outlook-2015.html

IEA, NEA. Projected Costs of Generating Electricity [Internet]. Paris, France and Issy-les-Moulineaux, France: International Energy Agency and Nuclear Energy Agency; 2010. Available from: http://www.worldenergyoutlook.org/media/weowebsite/energymodel/ProjectedCostsofGeneratingElectr icity2010.pdf

IEA/NEA. Projected Costs of Generating Electricity [Internet]. Paris, France: International Energy Agency (IEA) and Nuclear Energy Agency (NEA); 2015. Report No.: ISBN 978-92-64-24443-6. Available from: https://www.iea.org/bookshop/711-Projected_Costs_of_Generating_Electricity

IEA, World Bank. Sustainable Energy for All 2015-Progress Toward Sustainable Energy. Washington, DC: International Energy Agency (IEA) and World Bank; 2015 Jun. Report No.: Doi: 10.1596/978-1-4648 -06902 License: Creative Commons Attribution CC BY 3.0 IGO.

IRENA. Southern African Power Pool: Planning and Prospects for Renewable Energy [Internet]. Abu Dhabi, United Arab Emirates: International Renewable Energy Agency; 2013a. Available from:

http://www.irena.org/menu/index.aspx?mnu=Subcat\&PriMenulD=36\&CatID=141\&SubcatID=332

IRENA. West African Power Pool: Planning and Prospects for Renewable Energy [Internet]. Abu Dhabi, United Arab Emirates: International Renewable Energy Agency; 2013b. Available from: http://www.irena.org/menu/index.aspx?mnu=Subcat\&PriMenulD=36\&CatID=141\&SubcatID=333

Kemausuor F, Adkins E, Adu-Poku I, Brew-Hammond A, Modi V. Electrification planning using Network Planner tool: The case of Ghana. Energy for Sustainable Development. 2014 Apr;19:92-101.

Kenya Ministry of Energy. Updated Least Cost Power Development Plan Study Period: 2011-2031. Nairobi, Kenya; 2011 Mar p. http://erc.go.ke/images/docs/Least_Cost_Power_Development_Plan_2011-31.pdf.

Khatib H. A review of the IEA/NEA Projected Costs of Electricity - 2015 edition. Energy Policy. 2016 Jan;88:229-33.

Kost C, Mayer JN, Thomsen J, Hartmann N, Senkpiel C, Philipps S, et al. Levelized Cost of Electricity Renewable Energy Technologies [Internet]. Freiburg, Germany: Fraunhofer Institute for Solar Energy Systems ISE; 2013 Nov. Report No.: Thomas. Available from: https://www.ise.fraunhofer.de/en/publications/veroeffentlichungen-pdf-dateien-en/studien-undkonzeptpapiere/study-levelized-cost-of-electricity-renewable-energies.pdf

Levin T, Thomas VM. Least-cost network evaluation of centralized and decentralized contributions to global electrification. Energy Policy. 2012 Feb;41:286-302.

Levin T, Thomas VM. A mixed-integer optimization model for electricity infrastructure development. Energy Systems. 2013;4(1):79-98.

Levin T, Thomas VM. Modeling the impact of stochastic outages for electricity infrastructure development. Energy Syst. 2014a Sep 1;5(3):519-50.

Levin T, Thomas VM. Utility-maximizing financial contracts for distributed rural electrification. Energy. 2014b May;69:613-21. 
Lysen EH. Pico Solar PV Systems for Remote Homes [Internet]. International Energy Agency: Photovoltaic Power Systems Programme; 2013. Report No.: EA-PVPS T9-12:2012. Available from: http://iea-

pvps.org/index.php?id=299

Mainali B, Pachauri S, Rao ND, Silveira S. Assessing rural energy sustainability in developing countries. Energy for Sustainable Development. 2014 Apr;19:15-28.

Martin S, Susanto J. Supplying power to remote villages in Lao PDR. - The role of off-grid decentralised energy options. Energy for Sustainable Development [Internet]. 2014 in press [cited 2014 Feb 10]; Available from: http://www.sciencedirect.com/science/article/pii/S0973082613001245

MITEI. The Future of Solar Energy [Internet]. Cambridge, Massachusetts: Massachusetts Institute of Technology, Energy Initiative; 2015. Available from: https://mitei.mit.edu/futureofsolar

Murphy PM, Twaha S, Murphy IS. Analysis of the cost of reliable electricity: A new method for analyzing grid connected solar, diesel and hybrid distributed electricity systems considering an unreliable electric grid, with examples in Uganda. Energy. 2014 Mar 1;66:523-34.

NABARD. Operational Guidelines for Banks [Internet]. Mumbai, India: National Bank for Agriculture and Rural Development; 2011 May. Available from: https://www.nabard.org/pdf/Installation_of_solar.pdf

Narula K, Nagai Y, Pachauri S. The role of Decentralized Distributed Generation in achieving universal rural electrification in South Asia by 2030. Energy Policy. 2012 Aug;47(0):345-57.

Oladokun VO, Asemota OC. Unit cost of electricity in Nigeria: A cost model for captive diesel powered generating system. Renewable and Sustainable Energy Reviews. 2015 Dec;52:35-40.

Ouedraogo BI, Kouame S, Azoumah Y, Yamegueu D. Incentives for rural off grid electrification in Burkina Faso using LCOE. Renewable Energy. 2015 Jun;78:573-82.

Palit D, Chaurey A. Off-grid rural electrification experiences from South Asia: Status and best practices. Energy for Sustainable Development. 2011 Sep;15(3):266-76.

Parshall L, Pillai D, Mohan S, Sanoh A, Modi V. National electricity planning in settings with low pre-existing grid coverage: Development of a spatial model and case study of Kenya. Energy Policy. 2009 Jun;37(6):2395410.

Salvatore J. World Energy Perspective: Cost of Energy Technologies [Internet]. London, United Kingdom and New York, USA: World Energy Council and Bloomberg New Energy Finance; 2013. Available from: http://www.worldenergy.org/wpcontent/uploads/2013/09/WEC_J1143_CostofTECHNOLOGIES_021013_WEB_Final.pdf

Sanoh A, Kocaman AS, Kocal S, Sherpa S, Modi V. The economics of clean energy resource development and grid interconnection in Africa. Renewable Energy. 2014 Feb;62:598-609.

Sanoh A, Parshall L, Sarr OF, Kum S, Modi V. Local and national electricity planning in Senegal: Scenarios and policies. Energy for Sustainable Development. 2012 Mar;16(1):13-25.

SEIA. Solar Industry Facts: 2014 Year in Review [Internet]. Washington, DC: Solar Energy Industries Association; 2014 Dec. Available from: http://www.seia.org/sites/default/files/Q4\%202014\%20SMI\%20Fact\%20Sheet.pdf 
Szabó S, Bódis K, Huld T, Moner-Girona M. Energy solutions in rural Africa: mapping electrification costs of distributed solar and diesel generation versus grid extension. Environ Res Lett. 2011 Jul 1;6(3):034002.

Taliotis C, Bazilian M, Welsch M, Gielen D, Howells M. Grand Inga to power Africa: Hydropower development scenarios to 2035. Energy Strategy Reviews. 2014 Aug;4:1-10.

The World Bank. Enterprise Surveys: Infrastructure [Internet]. Washington, DC: The World Bank; 2012. Available from: http://www.enterprisesurveys.org

Urpelainen J. Grid and off-grid electrification: An integrated model with applications to India. Energy for Sustainable Development. 2014 Apr;19:66-71.

WEC/BNEF. World Energy Perspectives: Cost of Energy Technologies [Internet]. London, United Kingdom and New York, USA: World Energy Council (WEC) and Bloomberg New Energy Finance (BNEF); 2013 Oct. Available from: https://www.worldenergy.org/publications/2013/world-energy-perspective-cost-of-energytechnologies/

Wirth H. Recent Facts about Photovoltaics in Germany [Internet]. Freiburg, Germany: Fraunhofer Institute for Solar Energy Systems ISE; 2015 May. Available from: http://www.ise.fraunhofer.de/en/publications/veroeffentlichungen-pdf-dateien-en/studien-undkonzeptpapiere/recent-facts-about-photovoltaics-in-germany.pdf

World Bank. Reducing the Cost of Grid Extension for Rural Electrification [Internet]. Washington, DC: Energy Sector Management Assistance Programme; 2000. Available from: http://documents.worldbank.org/curated/en/2000/02/729124/reducing-cost-grid-extension-ruralelectrification

World Bank. Ghana: Poverty and Social Impact Analysis - Electricity Tariffs, June 2010 [Internet]. Washington, DC: The World Bank; 2010. Available from: http://siteresources.worldbank.org/INTPSIA/Resources/4900231120841262639/Ghana_PSIA_ElectricityTariffs.pdf

World Bank. Lighting Up Rural Communities in Bangladesh [Internet]. Washington, DC: The World Bank; 2014 Jan. Available from: http://www.worldbank.org/en/news/feature/2014/01/15/lighting-up-rural-communitiesin-bangladesh

Zerriffi H. From Acai to Access: Distributed Electrification in Rural Brazil. International Journal of Energy Sector. 2008;2:90-117.

Zerriffi H. Rural Electrification: Strategies for Distributed Generation. Dordrecht: Springer; 2011.

Zeyringer M, Pachauri S, Schmid E, Schmidt J, Worrell E, Morawetz UB. Analyzing grid extension and stand-alone photovoltaic systems for the cost-effective electrification of Kenya. Energy for Sustainable Development. 2015 Apr;25:75-86. 